The Geneva Papers on Risk and Insurance, 15 (No. 56, July 1990), 330-336

\title{
Liability Insurance in the Federal Republic of Germany
}

\author{
by Ernst Klingmüller*
}

\section{Introduction}

The continuing industrial development leads Liability Insurance into a new dimension. To her, the technological challenge which is hidden in the almost uncontrolled extension of possible causes for liability will be a question of fate: Will Liability Insurance will be able to meet the challenge in supplying sufficient coverage and a broad dimensioned regulation of damages?

Starting with an exemplifying presentation of newly developed forms of Liability Insurance, I would like to conclude my report with the discussion of possible structural changes and their limits resulting hereof.

\section{New Forms of Liability Insurance}

Liability Insurance is considered accessory notwithstanding whether the insured risk is an individual's or legal entity's liability to compensate the loss a third person suffers through the insured or co-insured. The introduction of new technologies and methods mounted the neccessity for Liability Insurance to adjust to new situations and perils by enlarging insurance cover or development of special liability policies for particular risks. As far as claims resulting out of breach of contract are involved, the concerned parties, i.e. insurer and policyholder, are held free to negotiate quality and extent of the insurance benefit for the occurred loss which the insured has to compensate. In this whole area the risk of random dominates in comparison to the risk of change as the latter can be contained by the concerned parties. This applies to legislative actions as well as court decisions where only few cases have been ruled as non-premeditated liability extension thus influencing the extent of coverage since they conjuncted damage causing facts to the insured risk which prior had not been thought about (i.e. liability extending to statements made in issuing prospectus).

Legislative actions and even far more court rulings have effectively influenced negligence as well as quasi-torts and strict liability in tort. This has been - and is - motivated by the attempt for a stronger consumer protection, holding that the individual seeking compensation will find a potent debtor in the Liability Insurance behind the tortfeasor which eventually provides the coverage. Repeatedly court rulings have created an extension of liability by expanding the nature of existing liability rules and thus consequently fitting them into a given coverage.

\footnotetext{
${ }^{*}$ Professor Dr. Klingmüller is Professor of Law Emeritus at the University of Köln. He also teaches at the University of Karlsruhe.
} 
This qualitative expansion leads to a quantitative increase of the damages to be paid by the insurer. Practically it is not the cover provided for catastrophes but the steady increase of normal liability insurances in the subsumption with regard to the damage to be paid which is considerably recognized. Since Liability Insurance is first risk insurance the premium rate is generally not affected by the development of the damage to be paid, as long as a separate premium adjustment has not been negotiated. But this must not be discussed in detail now.

A good example for the risk of change is the liability concept of the Motor Insurance and the loss of use of a vehicle for which the tortfeasor has to pay damages under the provisions of sec. $7 \mathrm{StVG}$ or sec. 823 para. $1 \mathrm{BGB}$ (Civil Code). This liability extension has been introduced by decisions of the Federal Court $(\mathrm{BGH})$ which favors compensatory damages on the grounds of a very broad interpretation. This ruling led to new contents in existing Motor Insurance contracts without forcing contractual alteration or rescission.

Another example is given by medical liability for personal damages suffered because of incurred malpractice. In these cases medical liability - out of reasons of evidence - is often founded on the grounds that the physician has informed the patient insufficiently about the possible risk of a personal injury or disability because in so far a consent of the patient had not been given. Since the patient does not have to prove malpractice but can recover on the grounds of not consenting to medical treatment leading to injury out of malpractice, the physician bears the burden of exculpation which he often cannot provide for in the required extent. He has no legal justification for the treatment leading to malpractice and consequently is held liable for a non-consented and thus unjustified personal injury or disability resulting out of medical malpractice. The higher the standards for medical information the higher the possibility to be held liable for medical malpractice. However, unforseeable complications during surgery may lead to the assumption of implied consent but the courts have constructed very narrow boundaries where this is tolerated.

Meanwhile physicians and hospitals have reacted to this development with considerable success by providing the patient with extensive formulated risk information prior to medical treatment combined with a declaration of consent to be signed by the patient. Especially the extensive risk information has resulted in many patients undergoing medical treatment with considerable uneasiness.

Yet another new concept of liability developed by court decisions extrapolating the general principles of Tort Law is Product Liability which is covered by a specially developed Business Liability Insurance.

The leading case (Hühnerpest-Urteil) implemented a shift in the burden of proof on the issue of negligence to the defendant manufacturer and has developed to a general rule for damages resulting out of technical spheres. The idea was that in many cases the injured claimant had no or only a diminishing possibility to pinpoint the technical malfunctioning production process and the defendant producer had a presupposed omniscient position. Therefore he was held responsible for a product with defective design, manufacturing defects as well as insufficient supervision of manufacture or failure to instruct the consumer as to the proper usage of the product. Meanwhile the Federal Court has gone as far as imposing a "post-sale" or better subsequent duty to warn for latent product defects which were not recognizable when the product was originally distributed. 
The insurance industry held pace with this development by constructing a special policy which covers the manufacturer's liability for damages caused by defective products in the course of which the costs of a recall action are insured separately or have to be expressly included. Necessary limitation of the liability for damages is granted by several measures. Besides the customary liability ceiling for the singular insured event there is a special regulation for identical items suffering from the same defect. These are added up as a single damage position and are limited by a single or multiple aggregate liability ceiling.

The original view - resulting out of an old tradition - that the defect in the damaged product itself is not covered, has been differentiated for larger units as they are considered divisible when they are a conglomerate of separate component parts. Damage incurred to the product as a whole or other components from a separate component part is subject to Product Liability insurance regardless of the manufacturing origin of the defect causing component.

With the enactment of the Council Directive for Defective Products and its implementation by the member states of the EC a step has been taken from liability based on fault ameliorated by shifting the burden of proof for negligence to the manufacturer to strict liability whereas the producer is liable for personal and property damage caused by a defective product. Damages to the defective product itself are excluded.

Regarding a recent Federal Court decision, it has to be noted that liability is also excluded for products that have not been defective at the time they were put into circulation. This recent decision - based on negligence (sec. 823 para. $1 \mathrm{BGB}$ ) - ruled that the producer is held liable up to the limits of his technical and economical potential to prevent that his product will cause bodily injury to a consumer. This duty may exceed well over the moment of distribution. In this judicial precedent the Federal Court went as far as to say that a producer and bottler of mineral water has to consider a possible impairment of his product on its way to final distribution. By attaching this far-reaching risk to the producer it was the latter who had to prove that he has not acted negligently in the course of this process which can hardly be fitted into technical production anymore. In this decision the burden of proof was not only shifted for negligence but also for causation by stating that the defences against an assumed causal link between defect and damage for which the producer carries the burden of refuting proof lose their impact when the nature of the defect is considered to be typically and most commonly encountered in the sphere of the producer. Therefore it is he who is held responsible to ensure himself in a reliable manner about the safety of the product, whereas the injured claimant only has to establish that the producer has handled his duty to secure the status of this safety in an insufficient manner. This results in the producer's obligation to offer proof that his product was not defective when put into circulation by him.

The opening of this possibility to shift the burden of proof for the causal link continues to stand in tradition with prior decisions by the Federal Court to lighten the burden of proof for the claimant. It remains to be seen as to how these principles for proof of causation will be received in the new Product Liability Act. It should be noted that the Federal Court has backed his decision by referring to similar strands of argumentation in the field of medical malpractice where the physician is encountered with a similar duty to secure medical findings lest he wants to carry the burden of the impossible clarification of a feasible causal link between incurred injury and medical practice. 
In the future claims will be based both on fault with shifted burden of proof and the new Product Liability Act similar to the situation already encountered with in Automobile Accident cases where compensation can be obtained on the grounds of sec. $7 \mathrm{StVG}$ or sec. $823 \mathrm{BGB}$.

The new Product Liability Act holds the producer liable as long as he cannot establish one of the given defences. The prime defence is the proof that the product was free from the damaging defect when it was put into circulation. The aforementioned decision of the Federal Court will play an important part here. Product Liability will be two-folded wherein the new Product Liability Act is a little bit narrower since only property damage caused by products of a type ordinarily intended for private use or consumption and actually used or consumed this way with a lower threshold than 1.125,- DM is compensated and personal damages are limited at 160 mill. DM. It has to be noted that an unforeseeable development risk - a defect that the state of scientific and technical knowledge at the time when the product was put into circulation was not able to detect or think of - is excluded from strict liability at least for the next ten years.

The strict liability regime of the Product Liability Act grants no compensation for pain and suffering. The injured claimant can obtain this compensation only on the grounds of para. 823 BGB.

Other than most of the countries who file liability for pharmaceuticals under general product liability the Federal Republic of Germany has enacted in 1978 a statute creating strict liability for producers of defective pharmaceuticals. A liability ceiling exists at $500.000,-$ DM or $30.000,-$ DM annuity for personal damages and a total liability ceiling of 200 mill. DM or 3 mill. DM annuity for so-called batch damages as first encountered with the Thalidomide cases. Section 84 of the Act holds manufacturers liable regardless of fault if damage caused by a drug exceeds the standard "acceptable in the light of results obtained by medical science," thereby exempting development risk from coverage. The Act applies to production defects, design defects, and the failure to label the drug properly.

A special liability regulation for personal injury has been put out for tested subjects (sec. 40). Since the testing of pharmaceuticals generally takes place with the consent of the subject tested, clinic personnel cannot be held liable. Insurance is nevertheless ordered for the case of death or lasting impairment and should cover at least 0.5 mill. DM. It is slightly comparable to accident insurance with the major difference that a certain lump sum is not negotiated.

This thought of compensation without scrutinizing negligence or causation is the basic concept of the due Air Passenger Insurance which has to be contracted for every air passenger at a sum of $35.000,-$ DM. The insured event is death or lasting impairment in the course of air traffic. The air transporter carries the burden of proof refuting his negligence. If proof cannot be established full liability finds its ceiling at 320:000,- DM.

Generally all these statutes just as their antecedent, the Liability Act 1871, last revised 1978 regulating the liability for railroad and hazardous facilities or the Road Traffic Act, have retained a ceiling for damages resulting out of accidents; the first with an annuity up to $30.000,-$ DM for each person killed or injured and $100.000,-$ DM for damage to property, $500.000,-$ or $750.000,-$ DM lump sum for injury to several people or 
30.000/45.000 DM annuity, respectively. The Nuclear Liability Act grants unlimited compensation for reactor accidents but in reality coverage is only provided up to 500 mill. DM and another 500 mill. DM governmental liability, respectively.

Disregarding the less important animal liability - sec. 833 para. 1 BGB - the unlimited strict liability stated in sec. 22 Water Resources Management Act stands as the only exception in the concept. This regulation has received special significance due to the contamination of drinking water resources underground by waste deposits and possible large quantity damages caused by industrial mishaps. Liability for contaminated realty proves to be difficult in that establishing responsibility a tortfeasor has to be defined for the different degrees of contamination. A task which is complicated when the lot or premises have changed owners several times before contamination was detected. At the same time it is considered doubtful whether strict liability can be established for contamination taking place prior to existence of the Act (1960). Nevertheless the duties put forth by sec. 22 are considered to have model character for a possible all-embracing Environmental Pollution Liability Bill especially since the principal regulation for environmental protection in sec. 16 Federal Environmental Protection Act does not include a liability scheme.

Even when curtailing the definition of the term environment to the elements water, soil and air, grasping a liable tortfeasor is difficult; the prevailing theory of causation is often not able to provide acceptable results due to the complexity of the enclosed elements and the fact that often an unpremeditated conjunction of substances in their chemical reaction prove to turn out harmful and hazardous. In case that immediate causation cannot be proved it has to be tried to be reached by the element of gradual possibility as to single industrial plants can be considered as potential i.e. possible polluters even though the facilities involved are approved. It has been ruled that the facility's accordance with an approval is no defence against liability for environmental damages caused by pollution. If an ex-post analysis shows that "approved environmental pollution" leads to severe damage the owner of the facility can be held liable for the concrete damage to the environment.

So far the heads of damage which can be attributed to the polluter have not been scrutinized as far as they extend above direct damage to property and personal damages. With this I am aiming at direct interferences to nature, especially the extinction of species in flora and fauna by industry caused environmental pollution, starting with different species protected by Law on to the changing of the biochemical compositions of the Rhine River, for example caused by contaminated sewage and alteration of the water temperature due to industrial and nuclear waste products. As far as the immediate polluter can be determined a restitution with public funds seems feasible; in many cases however restitution is not possible anymore and similar problems turn out when the damage has been caused cumulatively. A classical example is provided by the phenomenon "acid rain" whose composition and causation cannot be confined into national borders.

\section{Possible Changes}

The Age of Technology confronts our system of liability with a number of genuine problems. The introduction of strict liability to approved industrial plants would put compensation for damages which result out of justified and governmentally approved actions in the vicinity of levies. De lege lata, property loss and personal damages caused and related to an approved production process can only be compensated under the provision 
of sec. 906 Civil Code (BGB). With the introduction of the aforementioned, causation as the sole factor to establish responsibility apparently gains importance.

Allowing prima facie evidence to establish causation or the simple possibility of a causal link, the position of the insured claimant is decisively improved without alteration of insurance coverage provided that court rulings continue on this once taken path. In addition it has to be remembered that unrecognizable diluted pollutants may effect dangerous chemical reactions today in unison with other substances without sufficient possibilities on our hands to ascertain the exact moment of this damage-causing mishap.

Thus the question regarding the definition of the insured event obtains a new aspect just the same as grasping and classifying of summation damages since it is doubtful whether the traditionally understood definition of an insured event is applicable. The dangerous conjunction could be seen as an instigating permanent condition that may grow acute only after an uncalculable span of time. The emission of the different substances the components of the pollutant - may have occurred at different times. An imaginable situation if you consider layed-off waste deposit sites, for instance. The efficiency of the traditional gradual memorandum clause ("Allmählichkeits-Ausschlußklausel") in those cases is doubtful.

In other fields responsibility of different polluters can satisfactorily be established for single summation damages only on the grounds of the possibility of causation. Often the lack of a reliable basis will frustrate attempts to develop this possible root of causation. For instance, the amount of polluting substances might be as important as the degree to which the emission can be considered as dangerous. Furthermore the distance of the industrial plants emitting pollutants could play an important part in allocating liability for air pollution. These considerations also apply to the presently discussed general strict liability for environmental pollution derived out of sec. 22 Water Resources Management Act which should be enacted for all facilities capable of a considerable alteration to the physical, chemical or biological conditions of water, soil or air.

Another item critically annotated is the definition of damages. Presently, only personal damages, property loss and damages arising out of the loss are covered. Compensable losses of property according to the provision of secs. 90 et seq. Civil Code (BGB) are only those damages which are inflicted on a bodily substance and which are owned by the injured claimant. When public-owned property is involved, concretisation of the damage leads to difficulties, since restitutio in integrum sometimes is not feasible.

Allow me to exemplify the problem rather extremely: Can the extinction of certain species be considered as damages when this happens in the course of cultivating swamplands and marshes? An ecologist would most certainly approve of this. On the other hand the extinction of, for instance, fresh water crayfish caused by salty sewage that is followed by salt water crayfish developing a new habitat there, can hardly be considered as damage anymore. It occurs to me that the limits of a dogmatically founded liability are reached in those situations.

At last I want to annotate the extent of liability. Surely, not only normal damages but also major or even catastrophic ones such as Bhopal, Windskal and Chernobyl have to be 
covered and paid for. On the other hand especially the latter exemplifies that it is the realisation which has to be considered in those total liability claims.

Putting the limits of a Liability Insurance cover for general industrial strict liability too high would result in overtaxing even larger industrial facilities. When liability is overstretched in quantitative terms, for instance by including all ecological damages, the premiums for a Liability Insurance will have to rise in an economically irresponsible manner since Insurance has to be obtained for regulation of common damages. Advice and premium policies of the Insurance Industry may supply a humble contribution to loss prevention which should not be overestimated since loss prevention is primarily dealt with by the factory inspectorate.

For the cover of catastrophic damages financial backup will have to be supplied by some sort of governmental guarantee but even here Liability Insurance stays indispensable, because it is far too costly to establish a regulation department managing these governmental funds instead of delegating these tasks to Liability insurers.

Finally it has to be taken into account that completely overdimensioned catastrophic damages - from a material viewpoint - can only be compensated gradually. The aim should be a sensible interdependency between the material side of economy and the financial actuarial side of insurance. 